\title{
The Relationships between Early Trauma, Dissociation, and Alexithymia in Alcohol Addiction
}

\author{
Giuseppe Craparo ${ }^{\bowtie}$, Vittoria Ardino ${ }^{2}$, Alessio Gori ${ }^{3}$, and Vincenzo Caretti ${ }^{4}$ \\ ${ }^{1}$ Faculty of Human and Social Sciences, University of Enna Kore, Enna, Italy \\ 2PSSRU Unit Department of Social Policy, London School of Economics and Political Sciences, London, United Kingdom \\ ${ }^{3}$ Department of Psychology, University of Florence, Florence, Italy \\ ${ }^{4}$ Department of Psychology, University of Palermo, Palermo, Italy
}

Objective Addiction is often considered a dissociative behavior that is related to alexithymia and developmental trauma. The study aims were to explore the relationships between early trauma, alexithymia, and dissociation.

Methods A total of 117 (males=60; females $=57$ ) alcohol-addicted individuals and 117 healthy individuals (males $=60$; females $=57$ ) were administered a series of self-report questionnaires that assess traumatic experiences, alexithymia, and pathological dissociation.

Results Correlation analyses indicated significant correlations between alexithymia, dissociation, and trauma and a significant difference between the target and control groups, with higher alexithymia and dissociation scores in the target group.

Conclusion These findings suggest that trauma, alexithymia, and dissociation are predictors of alcohol addiction.

Psychiatry Investig 2014;11(3):330-335

Key Words Alcohol addiction, Dissociation, Alexithymia, Early trauma.

\section{INTRODUCTION}

Alcohol addiction is a major public health issue worldwide ${ }^{1}$ and is associated with a range of psychiatric disorders. ${ }^{2-4} \mathrm{Re}-$ search has indicated that childhood trauma is a predictor of the co-occurrence of trauma-related disorders ${ }^{5-7}$ and alcohol dependence. ${ }^{8,9}$ Several studies have shown a relationship between alcohol dependence, post-traumatic stress disorder, ${ }^{10-14}$ and dissociation. ${ }^{9-17}$ Alcohol abuse may, therefore, constitute one component of a constellation of psychopathological responses to trauma. ${ }^{12}$

Early trauma disturbs the development of cognitive and affective processing, the integration of thinking and feeling, and the capacity to understand and express emotional states; these disturbances are linked to post-traumatic reactions, dissocia-

Received: May 14, 2013 Revised: September 12, 2013

Accepted: October 7, 2013 Available online: July 21, 2014

$\triangle$ Correspondence: Giuseppe Craparo, $\mathrm{PhD}$

Faculty of Human and Social Sciences, University of Enna Kore, Cittadella Universitaria, CAP 94100, Enna, Italy

Tel: +39 0935536536, Fax: +390935536943

E-mail: giuseppe.craparo@unikore.it

(a) This is an Open Access article distributed under the terms of the Creative Commons Attribution Non-Commercial License (http://creativecommons.org/licenses/bync/3.0) which permits unrestricted non-commercial use, distribution, and reproduction in any medium, provided the original work is properly cited. tion, and alexithymia. ${ }^{18,19}$ Alexithymia is a multifaceted construct that represents difficulty in identifying, describing, and analyzing emotions and an externally oriented cognitive style. ${ }^{20}$ The inability to identify or name emotions, coupled with the feeling of being overwhelmed, may cause individuals to experience trauma. These individuals may become accustomed to expressing their affect ${ }^{21}$ through the development of a compensatory, non-verbal strategy, such as pathological drinking, to disrupt a sense of psychological numbing and/or to avoid and manage intense, seemingly uncontrollable emotions. ${ }^{18}$

Recently, alexithymia has been examined as a possible predictor of dissociative tendencies. ${ }^{8-25}$ Indeed, some theorists have suggested that alexithymia may be a reaction to early interpersonal traumas, such as abuse, ${ }^{26}$ and is a dysfunctional coping mechanism that "numbs" ${ }^{\text {"1 }}$ the buffer between bodily sensations and emotions. ${ }^{27}$ This numbness has often been observed in individuals with dissociative disorders. Higher rates of illness, anxiety, ${ }^{28,29}$ and depression have consistently been linked with the traumatic triad of alexithymia, alcohol, and dependency. ${ }^{30-32}$

Dissociation may interfere with the connections between affects, cognitions, and voluntary behavior control by influencing the development of alexithymia and resulting in the "dis- 
sociation" of the physiological, cognitive, and affective components of emotions. Both dissociation and alexithymia have been considered impairments of emotive perception that help trauma survivors manage overwhelming or difficult affective states. ${ }^{33}$ Several studies have investigated the impact of trauma on alexithymia. ${ }^{34,35}$ In some cases, including in a study on dissociation, ${ }^{17}$ the emotional experience itself was influenced. ${ }^{36}$ Frewen and colleagues ${ }^{37}$ conducted a meta-analysis that showed that individuals with post-traumatic stress disorder (PTSD) have a greater difficulty in identifying, describing, and experiencing emotions compared to individuals with no PTSD symptoms.

However, little is known about the interplay between early trauma, alexithymia, and dissociation. Research has yet to clarify the direction of causality and the specific role of dissociation in the development of alexithymia or vice versa. ${ }^{38}$ The current study aimed to explore the incidence of early trauma, alexithymia, and dissociation and to better understand the interaction between alexithymia, dissociation, and trauma in a sample of individuals with alcohol abuse. This population was selected because several studies have found that alcohol-dependent individuals often present a history of early trauma (mainly childhood abuse and neglect) in conjunction with alexithymic traits and dissociative tendencies. ${ }^{39,40}$ The present study's main hypothesis was that alexithymia and dissociation would be associated with alcohol consumption and severity in individuals with a history of trauma. Furthermore, it was hypothesized that a higher prevalence of a traumatic history, alexithymia, and dissociation would present in the alcoholdependent group compared to a control group of healthy individuals.

\section{METHODS}

\section{Participants}

The study population was selected from patients with an alcohol problem who had consulted local Mental Health Departments clinics in a city of Southern Italy as well as individuals without the disorder who inhabited the city. The inclusion criterion consisted of a diagnosis of alcohol-dependence in accordance with the DSM-IV-TR ${ }^{41}$ criteria. All participants were evaluated before pharmacotherapy (including anti-craving medication) was introduced. Exclusion criteria included a co-morbid psychiatric disorder (e.g., schizophrenia), an organic brain syndrome, and poly-substance use.

The final sample included 234 individuals (120 males and 114 females). Participants were divided into two groups, a target group and a control group. The target group consisted of 117 participants who were recruited from an outpatient program for alcohol-dependence in Southern Italy (males=60, fe- males=57), with an age range from 19 years to 66 years $(M=$ $44.85 ; \mathrm{SD}=9.94)$. In this group, 62 (53\%) had graduated from primary school, 48 (41\%) had graduated from high school, and 7 (6\%) were university graduates. The control group matched the target group on gender (males $=60$, females $=57$ ), with an age range from 20 years to 66 years $(M=43.98 ; S D=9.57)$. The level of education in the control group was higher than that in the target group, as $84(72 \%)$ had graduated from high school and $33(28 \%)$ were university graduates. The control group consisted of volunteers who were self-declared non-drinkers. The data showed no significant age difference between the target and control groups [t(116) $=0.697, \mathrm{p}=0.487]$.

\section{Measures}

The Dissociative Experiences Scale-II (DES-II) ${ }^{42}$ is a 28 -item self-report scale. This scale is not a diagnostic tool; rather, it serves as a screening device for chronic dissociative disorders. Respondents are asked to rate various dissociative experiences that occur in their daily life when they are not under the influence of alcohol or drugs. The reliability and validity of the Italian version of this scale are as high as those of the original form, ${ }^{43}$ with a good Cronbach's alpha $(0.81-0.94)$. Scores range from $0 \%$ to $100 \%$, with a cut-off of $\geq 30 \%$ representing potential dissociative mental states.

The Toronto Alexithymia Scale-20 (TAS-20) ${ }^{44}$ is a 20 -item self-report that assesses alexithymia. It has a three-factor structure, as follows: 1) Difficulty Identifying Feelings (DIF); 2) Difficulty Describing Feelings (DDF); 3) Externally Oriented Thinking (EOT). Cut-off scores have been established to categorize individuals as alexithymic ( $\geq 61)$, borderline (52-60), and non-alexithymic $(\leq 51)$. The TAS-20 has shown adequate validity and reliability $(\alpha=0.81 ; \mathrm{r}=0.77)$. The Italian version ${ }^{45}$ also demonstrates good internal consistency (Cronbach's alpha of 0.75 and 0.82 in normal and clinical groups, respectively).

The Traumatic Experiences Checklist (TEC) ${ }^{46}$ is a self-report measure that assesses 29 potentially traumatizing events, such as emotional abuse, neglect, sexual assault, and physical abuse. The TEC also addresses trauma severity across the following four variables: 1 ) event occurrence; 2) early traumatic experiences; 3 ) the duration of trauma; 4) subjective reaction to trauma.

\section{Procedure}

Alcohol-dependent participants were recruited from NHS outpatient clinics for substance abuse treatment in a region of Southern Italy. The control group included normal subjects who were matched on age and sex. A plain language statement was attached to the front of the questionnaires to explain the nature of the study. Participants were asked to be as honest and spontaneous as possible in their responses and were as- 
sured of anonymity and confidentiality. Participants returned their completed questionnaires to health professionals at the outpatient clinics or to a university office in a sealed envelope supplied by the researcher. All participants provided informed consent and were given the opportunity to withdraw from the study at any time. Furthermore, participants were later debriefed about the study by NHS staff. The study obtained ethics approval from the university that employed the principal investigator and the NHS ethics committee.

\section{Data analysis}

The statistical package SPSS 18 for Windows was used for all analyses (SPSS, Chicago, IL, USA).

Descriptive statistics were performed across all study variables. A paired t-test was used to compare the two groups.

A series of two-tailed Pearson linear correlations were conducted to test the relationships between variables.

Furthermore, a stepwise linear regression was used to analyze the relationship between variables.

\section{RESULTS}

In the target group, the TAS-20 mean score (Table 1) showed a borderline alexithymia threshold $(M=58.92, \mathrm{SD}=15.19)$. By contrast, the control group presented a mean score below the cut-off for alexithymia $(\mathrm{M}=47.24, \mathrm{SD}=13.35)$.

Half of the target group ( $\mathrm{N}=58,49.57 \%$; 22 males, 36\%; 36 females, $64 \%$ ) had alexithymia (TAS-20 total score $\geq 61$ ). Chi square tests revealed an effect of gender on both the TAS-20 total score $\left(\chi^{2}=9.45, \mathrm{df}=1, \mathrm{p}=0.002\right)$ and the Difficulty Identifying Feelings score $\left(\chi^{2}=17.26, \mathrm{df}=1, \mathrm{p}<0.001\right)$. By contrast, only 18 individuals in the control group (7 males, $11.6 \% ; 11$ females, $19.2 \%$ ) displayed alexithymic symptoms. In this group, there were no gender differences in the TAS-20 total score or its three factors (Table 2).

For the DES-II scores, the target group displayed a mean score $(M=32.61 ; S D=23.05)$ above the clinical cut-off, whereas the mean score of the control group was under the clinical cut-off $(\mathrm{M}=12.87 ; \mathrm{SD}=9.41)$ [ $\mathrm{t}(116)=8.32, \mathrm{p}<0.001]$. There were no significant gender differences within the two groups $\left(X^{2}=n s\right)$.

The TEC total score indicated a higher prevalence of traumatic events in the target group $(\mathrm{M}=4.85, \mathrm{SD}=5.44)$ compared to the control group $[\mathrm{M}=2.56, \mathrm{SD}=2.45 ; \mathrm{t}(116)=4.09, \mathrm{p}<0.001]$. In particular, emotional abuse $[\mathrm{t}(116)=3.61, \mathrm{p}<0.001]$ and physical abuse $[\mathrm{t}(116)=3.40, \mathrm{p}<0.001]$ showed significant differences. Alcohol-dependent individuals $(M=11.85, \mathrm{SD}=9.65)$ had experienced a traumatic event at an earlier age than controls $(\mathrm{M}=18.24, \mathrm{SD}=12.40)[\mathrm{t}(80)=-4.13, \mathrm{p}<0.001]$. There were no significant gender differences in the typology of trauma within the two groups.

\section{Correlations among variables in the alcohol- dependent group}

The TEC total score was positively correlated with only the DES-II ( $r=0.22, p<0.05)$. With respect to specific types of traumatic experiences, we found significant correlations (Table 3 ) between emotional abuse and dissociation $(\mathrm{r}=0.28, \mathrm{p}<.01)$, physical abuse and the DDF TAS-20 factor $(r=0.22, \mathrm{p}<0.05)$, physical abuse and dissociation $(\mathrm{r}=0.22, \mathrm{p}<0.05)$, sexual abuse and the TAS-20 total score $(\mathrm{r}=0.31, \mathrm{p}<0.01)$, sexual abuse and the DDF $(\mathrm{r}=0.31, \mathrm{p}<0.01)$, and sexual abuse and the EOT ( $\mathrm{r}=$ $0.36, \mathrm{p}<0.01)$. Dissociation was positively correlated with the TAS-20 total score $(r=0.60, p<0.01)$ and the three TAS-20 subscales (DIF, $\mathrm{r}=0.49, \mathrm{p}<0.01$; DDF, $\mathrm{r}=0.38, \mathrm{p}<0.01$; EOT, $\mathrm{r}=0.56$, $\mathrm{p}<0.01)$. An interesting outcome was the negative correlation between dissociation and early traumatic experiences $(r=-0.35$, $\mathrm{p}<0.01)$.

\section{Correlations among variables in the control group}

The data showed that dissociation was significantly and positively correlated with the TAS-20 total score $(\mathrm{r}=0.36, \mathrm{p}<$ $0.001)$ and the DIF $(r=0.450, p<0.001)$ and DFF $(r=0.21, p<$ $0.05)$ TAS-20 factors. In the target group, the TEC total score was correlated with both the DIF TAS-20 factor and the DESII (Table 4). In regards to traumatic experiences, we observed

Table 1. Mean differences in trauma, alexithymia, and dissociation between the two groups of participants

\begin{tabular}{|c|c|c|c|c|c|c|c|c|}
\hline & \multicolumn{4}{|c|}{ Alcohol-dependent group } & \multicolumn{4}{|c|}{ Control group } \\
\hline & M & $\mathrm{SD}$ & $\mathrm{N}$ & Missing & M & $\mathrm{SD}$ & $\mathrm{N}$ & $\mathrm{p}$ value \\
\hline TAS-20 & 58.92 & 15.19 & 115 & 2 & 47.24 & 13.35 & 117 & 0.000 \\
\hline DIF & 22.34 & 8.14 & 115 & 2 & 14.54 & 6.35 & 117 & 0.000 \\
\hline DDF & 15.07 & 0.72 & 115 & 2 & 13.01 & 5.03 & 117 & 0.001 \\
\hline EOT & 21.51 & 6.04 & 115 & 2 & 19.68 & 5.17 & 117 & 0.018 \\
\hline DES-II & 32.61 & 23.05 & 117 & 0 & 12.87 & 9.41 & 117 & 0.000 \\
\hline TEC & 4.85 & 5.44 & 117 & 0 & 2.56 & 2.45 & 117 & 0.000 \\
\hline
\end{tabular}

TAS-20: Twenty-Item Toronto Alexithymia Scale, DIF: difficulty modulating and identifying feelings, DDF: difficulty describing one's feelings to others, EOT: externally oriented thinking, DES-II: Dissociative Experiences Scale, TEC: Traumatic Experiences Checklist 
a significant correlation between the DES-II and emotional trauma.

\section{Predictive relationships among variables in the two groups}

A stepwise regression linear showed that the TAS-20 total

Table 2. Mean differences in trauma, alexithymia, and dissociation between males and females of the two groups

\begin{tabular}{|c|c|c|c|c|c|c|c|c|c|c|c|c|c|c|c|c|}
\hline & \multicolumn{8}{|c|}{ Alcohol-dependent group } & \multicolumn{8}{|c|}{ Control group } \\
\hline & \multicolumn{3}{|c|}{ Males } & \multicolumn{3}{|c|}{ Females } & \multirow{2}{*}{$\chi^{2}(1)$} & \multirow{2}{*}{$\mathrm{p}$} & \multicolumn{3}{|c|}{ Males } & \multicolumn{3}{|c|}{ Females } & \multirow{2}{*}{$\chi^{2}(1)$} & \multirow{2}{*}{$\mathrm{p}$} \\
\hline & $\mathrm{M}$ & SD & $\mathrm{N}$ & $\mathrm{M}$ & $\mathrm{SD}$ & $\mathrm{N}$ & & & $\mathrm{M}$ & SD & $\mathrm{N}$ & M & SD & $\mathrm{N}$ & & \\
\hline TAS-20 & 54.75 & 15.06 & 60 & 63.37 & 13.41 & $55(2)$ & 9.45 & 0.002 & 47.58 & 12.12 & 60 & 46.69 & 14.63 & 57 & 0.078 & 0.780 \\
\hline DIF & 19.32 & 7.53 & 60 & 25.64 & 7.55 & $55(2)$ & 17.26 & 0.000 & 13.51 & 5.72 & 60 & 15.63 & 6.84 & 57 & 3.23 & 0.072 \\
\hline DDF & 14.27 & 4.57 & 60 & 15.95 & 4.54 & $55(2)$ & 3.78 & 0.052 & 13.65 & 4.56 & 60 & 12.35 & 5.43 & 57 & 1.94 & 0.163 \\
\hline EOT & 21.17 & 6.87 & 60 & 21.89 & 5.03 & $55(2)$ & 0.41 & 0.521 & 20.41 & 5.26 & 60 & 18.91 & 5.00 & 57 & 2.47 & 0.116 \\
\hline DES-II & 29.45 & 23.35 & 60 & 35.94 & 22.46 & $57(0)$ & 2.31 & 0.128 & 11.75 & 7.69 & 60 & 14.05 & 10.88 & 57 & 1.74 & 0.186 \\
\hline TEC & 4.90 & 4.99 & 60 & 4.79 & 5.92 & $57(0)$ & 0.12 & 0.913 & 2.36 & 2.49 & 60 & 2.77 & 2.40 & 57 & 0.80 & 0.371 \\
\hline
\end{tabular}

TAS-20: Twenty-Item Toronto Alexithymia Scale, DIF: difficulty modulating and identifying feelings, DDF: difficulty describing one's feelings to others, EOT: externally oriented thinking, DES-II: Dissociative Experiences Scale, TEC: Traumatic Experiences Checklist

Table 3. Correlation matrix for all variables in the alcohol-dependent group

\begin{tabular}{|c|c|c|c|c|c|c|c|c|c|c|c|}
\hline Measure & 1 & 2 & 3 & 4 & 5 & 6 & 7 & 8 & 9 & 10 & 11 \\
\hline 1. Age & - & -0.13 & -0.08 & -0.04 & $-0.19 *$ & -0.16 & 0.06 & 0.03 & -0.04 & 0.09 & 0.09 \\
\hline 2. TAS-20 & & - & $0.88^{* *}$ & $0.80^{*}$ & $0.70^{* *}$ & $0.60^{* *}$ & 0.16 & 0.17 & $0.31^{* *}$ & $-0.22^{*}$ & 0.08 \\
\hline 3. DIF & & & - & $0.66^{*}$ & $0.37^{* *}$ & $0.49^{* *}$ & 0.10 & 0.09 & 0.14 & $-0.29 *$ & 0.02 \\
\hline 4. DDF & & & & - & $0.36^{* *}$ & $0.38^{* *}$ & 0.16 & $0.22^{*}$ & $0.31^{* *}$ & -0.08 & 0.17 \\
\hline 5. EOT & & & & & - & $0.56^{* *}$ & 0.14 & 0.12 & $0.36^{* *}$ & -0.14 & 0.06 \\
\hline 6. DES-II & & & & & & - & $0.28^{* *}$ & $0.22^{*}$ & $0.32^{* *}$ & $-0.35^{* *}$ & $0.22^{*}$ \\
\hline 7. Emotional abuse & & & & & & & - & $0.77^{* *}$ & $0.56^{* *}$ & $-0.41^{* *}$ & $0.88^{* *}$ \\
\hline 8. Physical abuse & & & & & & & & - & $0.75^{* *}$ & $0.30^{* *}$ & $0.89^{* *}$ \\
\hline 9. Sexual abuse & & & & & & & & & - & -0.14 & $0.75^{* *}$ \\
\hline 10. Early trauma & & & & & & & & & & - & -0.30 \\
\hline 11. TEC total score & & & & & & & & & & & - \\
\hline
\end{tabular}

*all coefficients are significant at the 0.05 level, ${ }^{* *}$ all coefficients are significant at the 0.01 level. TAS-20: Twenty-Item Toronto Alexithymia Scale, DIF: difficulty modulating and identifying feelings, DDF: difficulty describing one's feelings to others, EOT: externally oriented thinking, DES-II: Dissociative Experiences Scale, TEC: Traumatic Experiences Checklist

Table 4. Correlation matrix for all variables in the control group

\begin{tabular}{|c|c|c|c|c|c|c|c|c|c|c|c|}
\hline Measure & 1 & 2 & 3 & 4 & 5 & 6 & 7 & 8 & 9 & 10 & 11 \\
\hline 1. Age & & $0.33^{* *}$ & $0.29^{* *}$ & $0.23^{*}$ & $0.28^{* *}$ & 0.01 & 0.01 & $-0.19^{*}$ & -0.11 & 0.01 & 0.15 \\
\hline 2. TAS-20 & & & $0.84^{* *}$ & $0.82^{* *}$ & $0.75^{* *}$ & $0.36^{* *}$ & 0.12 & $-0.22^{*}$ & -0.14 & 0.04 & 0.06 \\
\hline 3. DIF & & & & $0.56^{* *}$ & $0.40^{* *}$ & $0.45^{* *}$ & 0.27 & -0.12 & -0.04 & $-0.05^{*}$ & $0.21^{*}$ \\
\hline 4. DDF & & & & & $0.45^{* *}$ & $0.21^{*}$ & 0.01 & $-0.21^{*}$ & -0.15 & -0.09 & -0.05 \\
\hline 5. EOT & & & & & & 0.17 & -0.02 & $-0.20^{*}$ & -0.16 & 0.07 & -0.06 \\
\hline 6. DES-II & & & & & & & $0.50^{* *}$ & 0.02 & 0.12 & -0.11 & $0.39^{* *}$ \\
\hline 7. Emotional abuse & & & & & & & & $0.48^{* *}$ & $0.20^{*}$ & $-0.39^{* *}$ & $0.82^{* *}$ \\
\hline 8. Physical abuse & & & & & & & & & $0.22 *$ & $-0.32^{* *}$ & $0.57^{* *}$ \\
\hline 9. Sexual abuse & & & & & & & & & & -0.10 & $0.35^{* *}$ \\
\hline 10. Early trauma & & & & & & & & & & & $-0.42^{* *}$ \\
\hline
\end{tabular}

11. TEC total score

*all coefficients are significant at the 0.05 level, **all coefficients are significant at the 0.01 level. TAS-20: Twenty-Item Toronto Alexithymia Scale, DIF: Difficulty modulating and identifying feelings, DDF: difficulty describing one's feelings to others, EOT: externally oriented thinking, DES-II: Dissociative Experiences Scale, TEC: Traumatic Experiences Checklist 
score predicted dissociation in the target group ( $\mathrm{F}=65.40$, $\mathrm{df}=1$, adjusted $\mathrm{R}^{2}=0.361, \mathrm{p}<0.001$ ). In the control group, only the DIF TAS-20 factor was a good predictor of dissociation $\left(\mathrm{F}=29.24, \mathrm{df}=1\right.$, adjusted $\left.\mathrm{R}^{2}=0.196, \mathrm{p}<0.001\right)$ (Table 2$)$.

\section{DISCUSSION}

This study confirmed the existing research regarding the role of trauma in addiction behavior. ${ }^{15,47,48}$ Alcohol dependency can be considered a dissociative reaction of individuals with difficulties in identifying, expressing, and regulating emotions. The present findings also showed that age at first traumatic experience (in particular, emotional abuse) plays a major role in activating dissociative reactions (such as, dissociative defense mechanisms and pathological alcohol consumption). ${ }^{49-54}$ Alexithymia, dissociation, and trauma are interrelated among individuals with alcoholism. This triad's relevance for the prevention and treatment of alcohol dependence requires attention in future studies. The current results suggest that addictive behaviors have a dissociative nature that allows individuals to manage negative and unregulated emotions.

The present study measured chronic (trait) dissociation rather than acute and transient dissociative states. Although chronic dissociation contributes to difficulties in identifying feelings, chemically (alcohol-induced) transient dissociative states may be a paradoxical effort to identify and express feelings that are otherwise difficult to access. Thus, alcohol appears to influence the interplay between trauma, dissociation, and alexithymia. This interplay may be an important factor in the prevention and treatment of alcoholism in the addicted population.

Given that this study was cross-sectional, the long-term stability of these findings requires further inquiry. Future research should also explore whether female patients display dissociative experiences and alexithymia profiles that differ from those of male patients.

\section{REFERENCES}

1. Harper C, Matsumoto I. Ethanol and brain damage. Curr Opin Pharmacol 2005;5:73-78.

2. Kushner MG, Abrams K, Borchardt C. The relationship between anxiety disorders and alcohol use disorders: a review of major perspectives and findings. Clin Psychol Rev 2000;20:149-171.

3. Lyne JP, O’Donoghue B, Clancy M, O'Gara C. Comorbid psychiatric diagnoses among individuals presenting to an addiction treatment program for alcohol dependence. Subst Use Misuse 2011;46:351-358.

4. Walvoort SJW, Wesyer AJ, Egger JIM. Assessment of psychopathology and personality with the MMPI-2 in Patients with alcohol use disorder (AUD): should we not correct for associated cognitive dysfunctions? Clin Neuropsychiatry 2012;9:212-220.

5. Gershuny BS, Thayer JF. Relations among psychological trauma, dissociative phenomena, and trauma-related distress: a review and inte- gration. Clin Psychol Rev 1999;19:631-657.

6. Chu JA, Dill DL. Dissociative symptoms in relation to childhood physical and sexual abuse. Am J Psychiatry 1990;147:887-892.

7. Craparo G. Internet addiction, dissociation, and alexithymia. Procedia Soc Behav Sci 2011;30:1051-1056.

8. Zlotnick C, Shea MT, Pearlstein T, Simpson E, Costello E, Begin A. The relationship between dissociative symptoms, alexithymia, impulsivity, sexual abuse, and self-mutilation. Compr Psychiatry 1996;37:12-16.

9. Evren C, Sar V, Evren B, Semiz U, Dalbudak E, Cakmak D. Dissociation and alexithymia among men with alcoholism. Psychiatry Clin Neurosci 2008;62:40-47.

10. Chilcoat H, Menard C. Epidemiological Investigations: Comorbidity of Posttraumatic Stress Disorder and Substance Use Disorder. In: Ouimette P, Brown PJ, Editors. Trauma and Substance Abuse: Causes, Consequences and Treatment of Comorbid Disorders. Washington, DC: American Psychological Publishing, 2003, p.9-28.

11. Faraci P, Craparo G, Messina R, Severino S. Internet Addiction Test (IAT): which is the best factorial solution? J Med Internet Res 2013;15: e225.

12. Foa EB, Williams MT. Methodology of a randomized double-blind clinical trial for comorbid posttraumatic stress disorder and alcohol dependence. Ment Health Subst Use 2010;3:131-147.

13. Craparo G, Faraci P, Rotondo G, Gori A. The Impact of Event Scale Revised: psychometric properties of the Italian version in a sample of flood victims. Neuropsychiatr Dis Treat 2013;9:1427-1432.

14. Bermond B, Moormann PP, Albach F, van Dijke A. Impact of severe childhood sexual abuse on the development of alexithymia in adulthood. Psychother Psychosom 2008;77:260-262.

15. Schäfer I, Langeland W, Hissbach J, Luedecke C, Ohlmeier MD, Chodzinski C, et al. Childhood trauma, dissociation and posttraumatic stress disorder in patients with alcohol dependence, drug dependence or both - a multi-center study. Drug Alcohol Depend 2010;109:84-89.

16. Franzoni E, Gualandi S, Caretti V, Schimmenti A, Di Pietro E, Pellegrini $\mathrm{G}$, et al. The relationship between alexithymia, shame, trauma, and body image disorders: investigation over a large clinical sample. Neuropsychiatr Dis Treat 2013;9:185-193.

17. Craparo G. Addiction, dissociation, and the unrepressed unconscious. A theoretical contribution from a developmental-relational perspective. Ric Psic 2013;2:73-84.

18. Yates TM. Developmental Pathways from Child Maltreatment to Nonsuicidal Self-Injury. In: Nock MK, Editor. Understanding Nonsuicidal Self-Injury: Origins, Assessment and Treatment. Washington, DC: American Psychological Association, 2009, p.117-137.

19. Craparo G, Faraci P, Fasciano S, Carrubba S, Gori A. A factor analytic study of the Boredom Proneness Scale (BPS). Clin Neuropsychitary 2013;10:164-170.

20. Nemiah JC, Freyberger H, Sifneos PE. Alexithymia: A View of the Psychosomatic Process. In: Hill OW, Editor. Modern Trends in Psychosomatic Medicine, Vol. 3. London: Butterworths, 1976, p.430-439.

21. van der Kolk BA, McFarlane AC, Weisaeth L. Traumatic Stress: The Effects of Overwhelming Experience on Mind, Body, and Society. New York: Guilford Press; 1996.

22. Berenbaum H, James T. Correlates and retrospectively reported antecedents of alexitymia. Psychosom Med 1994;56:353-359.

23. Craparo G, Faraci P, Fasciano S, Carrubba S, Gori A. A factor analytic study of the Boredom Preneness Scale (BPS). Clin Neuropsychiatry 2013;10:164-170.

24. Elzinga BM, Bermond B, van Dyck R. The relationship between dissociative proneness and alexithymia. Psychother Psychosom 2002;71:104111.

25. Grabe HJ, Spitzer C, Freyberger HJ. Alexithymia and the temperament and character model of personality. Psychother Psychosom 2001;70:261267.

26. Berenbaum H. Childhood abuse, alexithymia and personality disorder. J Psychosom Res 1996;41:585-595. 
27. Wise TN, Mann LS, Sheridan MJ. Relationship between alexithymia, dissociation and personality in psychiatric out patients. Psychother Psychosom 2000;69:123-127.

28. Fukunishi I, Rahe RH. Alexithymia and coping with stress in healthy persons: alexithymia as a personality trait is associated with low social support and poor responses to stress. Psychol Rep 1995;76:1299-1304.

29. Gori A, Giannini M, Socci S, Luca M, Dewey D, Schuldberg D, et al. Assessing social anxiety disorder: psychometric properties of the Italian social phobia inventory (I-SPIN). Clin Neuropsychitary 2013;10:37-42.

30. Honkalampi K, Hintikka J, Tanskanen A, Lehtonen J, Viinamäki H. Depression is strongly associated with alexithymia in the general population. J Psychosom Res 2000;48:99-104.

31. Marchesi C, Brusamonti E, Maggini C. Are alexithymia, depression, and anxiety distinct constructs in affective disorders? J Psychosom Res 2000;49:43-49.

32. Thorberg FA, Young RM, Sullivan KA, Lyvers M. Alexithymia and alcohol use disorders: a critical review. Addict Behav 2009;34:237-245

33. Sayar K, Kose S, Grabe HJ, Topbas M. The relationship between alexithymia and dissociation in an adolescent sample. Psychiatry Clin Neurosci 2005;59:127-134

34. Goldsmith R, Freyd JJ. Awareness for emotional abuse. J Emot Abuse 2005;5:95-123.

35. Zlotnick C, Mattia J, Zimmerman M. The relationship between posttraumatic stress disorder, childhood trauma and alexithymia in an outpatient sample. J Trauma Stress 2001;14:177-188.

36. Foa EB, Hearst-Ikeda D. Emotional Dissociation in Response to Trauma: An Information; Processing Approach. In: Michelson LK, Ray WJ, Editors. Handbook of Dissociation: Theoretical, Empirical, and Clinical Perspectives. NewYork: Plenum Press, 1996, p.207-224.

37. Frewen PA, Dozois DJA, Neufeld, RWJ, Lanius RA. Meta-analysis of alexithymia in posttraumatic stress disorder. J Trauma Stress 2008;21: 243-246.

38. Irwin HJ, Melbin-Helberg EB. Alexithymia and dissociative tendencies. J Clin Psychol 1997;53:159-166.

39. Bujarski S, Klanecky AK, McChargue DE. The relationship between alexithymia and alcohol-related risk perceptions: the moderating effect of general trauma in a college population. Addict Behav 2010;35:363-366.

40. Klanecky AK, Harrington J, McChargue DE. Child sexual abuse, dissociation, and alcohol: Implications of chemical dissociation via blackouts among college women. Am J Drug Alcohol Abuse 2008;34:277-284

41. American Psychiatric Association. Diagnostic and Statistical Manual of
Mental Disorders, Fourth Edition, Text revision. Washington D.C: American Psychiatric Press Inc; 1994.

42. Carlson EB, Putnam FW. An update on the dissociative experiences scale. Dissociation 1993;6:16-27.

43. Schimmenti A, Craparo G, Caretti V. Validity and reliability of the Revised Dissociative Experience Scale (DES-II) in an Italian sample. Unpublished manuscript. Faculty of Human and Social Sciences, Kore University, Enna.

44. Bagby RM, Taylor GJ, Parker JD. The Twenty-Item Toronto Alexithymia Scale-II. Convergent discriminant, and concurrent validity. J Psychosom Res 1994;38:33-40.

45. Bressi C, Taylor G, Parker J, Bressi S, Brambilla V, Aguglia E, et al. Cross validation of the factor structure of the 20 -item Toronto Alexithymia Scale: an Italian multicenter study. J Psychosom Res 1996;41:551-559.

46. Nijenhuis ERS. Somatoform Dissociation: Phenomena, Measurement, and Theoretical Issues. Assen, The Netherlands: Van Gorcum; 1999.

47. Najavits LM, Weiss RD, Shaw SR. The link between substance abuse and posttraumatic stress disorder in women. A research review. Am J Addict 1997;6:273-283.

48. Speranza M, Corcos M, Stéphan P, Loas G, Pérez-Diaz F, Lang F, et al. Alexithymia, depressive experiences, and dependency in addictive disorders. Subst Use Misuse 2004;39:551-579.

49. Craparo G, Faraci P, Rotondo G, Gori A. The Impact of Event Scale-Revised: Psychometric properties of the Italian version in a sample of flood victims. Neuropsychiatr Dis Treat 2013;9:1427-1432.

50. Faraci P, Triscari MT, D’Angelo V, Urso V. Fear of flying assessment: a contribution to the Italian validation of two self-report measures. Rev Psychol 2011;18:91-100.

51. Manna G, Faraci P, Como MR. Factorial structure and psychometric properties of the Sensation Seeking Scale - Form V (SSS-V) in a sample of Italian adolescents. Eur J Psychol 2013;9:276-288.

52. Giannini M, Gori A, De Sanctis E, Schuldberg D. Attachment in psychotherapy: psychometric properties of the psychological treatment inventory attachment styles scale (PTI-ASS). J Psychother Integrat 2011;21:363-381.

53. Craparo G, Schimmenti A, Caretti V. Traumatic experiences in childhood and psychopathy: a study on a sample of violent offenders from Italy. Euro J Psychotraumatol 2013;4. doi: 10.3402/ejpt.v4i0.21471.

54. Luca M, Giannini M, Gori A, Littleton H. Measuring dysmorphic concern in Italy: Psychometric properties of the Italian Body Image Concern Inventory (I-BICI). Body Image 2011;8:301-305. 